\title{
English Language Teaching in Multilingual Classrooms: A Study of L2 Teachers' Strategies to Manage Many Languages
}

\author{
Nazia Koonj \\ MS Scholar \\ English Language Development Centre (ELDC), Mehran University \\ of Engineering \& Technology, Jamshoro \\ Dr. Shumaila Memon \\ Associate Professor \\ English Language Development Centre (ELDC), Mehran University \\ of Engineering \& Technology, Jamshoro \\ Syed Waqar Ali Shah \\ Lecturer \\ English Language Development Centre (ELDC), Mehran University \\ of Engineering \& Technology, Jamshoro
}

\begin{abstract}
The teaching plus learning practices have become a challenge for ESL teachers and learners significantly at the undergraduate level in Pakistan. This difficulty occurs to teachers when they have to deal with ESL learners from such diverse backgrounds. In Pakistan, the English languages is majorly taught as second language at college and university levels in public and private sectors. At general level, English language is in practical pedagogy as a compulsory subject from schools to colleges and universities. The English language today is used as the world's language some also call it as "Universal language" because of its wide usage across the world, that contributes into the usage and learning of the language in all the domains and areas of study (Yunus, 2013). This research study attempted to investigate the strategies ESL teachers use in multilingual English language classrooms at undergraduate level in universities to deal with learners and cope up with such linguistic diversity in classrooms. The qualitative research paradigm was employed with structured online interviews of the undergraduate teachers of University of Sindh, Mehran University of Engineering and technology, Jamshoro, and Quaid-e-Awam University of Engineering, science and technology, Nawabshah, Sindh, Pakistan respectively. The study proposed that there are diversified learners in multilingual ESL classrooms at undergraduate level in universities having different backgrounds. The teachers use multiple strategies to cater multilingual learners in ESL classrooms and these situations have both positive and negative effects on learners' performances.
\end{abstract}

Keywords: English language teaching, English as Second language (ESL), learner's experiences, learner's difficulties, language learners, teacher's strategies, pedagogy.

DOI: $10.7176 /$ JLLL/64-02

Publication date: January $31^{\text {st }} 2020$

\section{Introduction:}

The learning experiences and real life practices become a challenge for both learners and teachers in English as second language classrooms in learning of English language. This is specifically present and observed mostly on the undergraduate level in third world countries. This difficulty occurs to students where the main problem comes where the learners have to communication and socialization in English as a norm in university inside and outside the classrooms. In Pakistan, the second language in use and academics in colleges and universities is majorly English. On general level, English language is in practical pedagogy as a compulsory subject from schools to colleges and universities. The English language today is used as the world's language some also call it as "Universal language" because of its wide usage across the world, that contributes into the usage and learning of the language in all the domains and areas of study. (Melor Md Yunus, 2013).

Some of the common problems that researchers have identified from the learners 'responses and their experiences of undergraduate studies have reflected for inflexibility in learning strategies, subject difficulty, reliance on teachers' techniques and methods, unorganized academic skills, lack of academic and intellectual competence, excessive workload to cover and lack of motivation that lead to a failure of education system. (Wankowski, 1991), (Upcraft, 1990), (Chambers, 1992), (Meyer, 1991).

The concept of multilingualism in linguistics refers to the sufficient knowledge of more than one languages. The schema of more than two languages in multilingualism must include the common rules and regulations which are used in writing and reading. Research has shown the rapid increase of multilingualism on official 
ground among countries like Canada, Switzerland and Belgium whereas, it has grown adequately in Asian and African countries of the world. The spread of multilingualism has a lot of factors some of important ones are the mixed language usages in the world in the form of lingua franca whereas, cross cultural interaction proves to be a greater source of spread of multilingualism around the world.

With the inclusion of more than one official languages there has been positive influence on regional and local languages as well. Since, $21^{\text {st }}$ century focuses on communication as the prime important factor of interaction around the world. This has proved to enhanced multilingualism better than before.

\subsection{Aims \& Objectives}

This research paper focuses on the learning situation and strategies of Multilingualism on learners and teachers part in ESL classroom context also the impact that is led by such situations like multilingualism. The following objectives were set:

1. To identify the impact of multilingualism on learners' performance in Undergraduate ESL classrooms at University of Sindh.

2. To investigate the strategies and techniques teachers' do to cater learners' from different multilingual backgrounds in Undergraduate ESL classrooms at University of Sindh.

\subsection{Research Questions}

This research paper aims to answer the following questions based on the research objectives of the study. They are as follows:

RQ1: What is the impact of Multilingualism on learners' performance in Undergraduate ESL classroom context at University of Sindh?

RQ2: What are the strategies used by teachers to cater such diverse multilingual learners in undergraduate ESL classrooms at University of Sindh?

\section{Literature Review:}

Human beings in nature want to have an organized way of communication in a particular society. The medium of communication is called as a language. The attempt is difficult to justify the role of language in a given society because of its complexity in usage, but linguistically it is believed that a language is composed of sequences of symbols and signs quantified for the exclusive purpose of communication. An organization that has a group of articles organized in such a way to fulfill a particular function with a proper combination of those articles. Language being a medium of communication has specific roles to perform in a context some of those functions are also called language attributes such as expression of ideas, thoughts and emotions, creating and maintaining identity marker, setting up a personality and many more. As the organization of communication and its attributes are many more to be described in lines so is the human nature with the compatibility of context. Now, this complexity and contextual variation of human nature gives a rise to the importance and usage of many local and regional languages. The concept of bilingualism and multilingualism has been emerged from such diversified languages and their usage in particular context.

This research study is focused on the diverse usage of multiple languages which can be studied under the term 'Multilingualism'. It is derived from the two Latin words 'multi-many' and 'lingua-language'. So, multilingualism denotes the capability of humans to use their communication skills in more than one languages in a clear and comprehendible manner with an equal, adequate and native like proficiency. Whereas, the researchers have proved that both of the mediums of expression verbal and written real life practices have one language in dominance on other languages in multilingual context.

Multilingualism is also called as phenomenon of having co-existence of several languages simultaneously in a given context. Those several languages have many purposes some of them are used for official purpose some for unofficial usage; others might have native or foreign, national and international purposes to serve.

In a given multilingual context the speakers of more than one languages have some traits that show the existence of many languages with a range of communicative competence. The tendency that shows a clear functional differentiation of two languages is generally referred to as diglossia. This term shows the difference of language varieties in terms of low and high usages in informal and formal meetings respectively.

Multilingualism has an effect on all the domains of study here the point of focus is a second language learning situation in which the learners belonging to a multilingual background are brought to sit and learn the same thing together without having additional benefits on their multiple languages. The phenomenon has a lot of impact proved by researchers on learners, teachers and on learning situations respectively.

The researchers like (Collier, 1997, 2002), (Cummins, 2000, 2001) and (Garcia, 2009) have stressed over the multilingualism classroom teaching and learning practices at undergraduate level in universities.

(Garcia, 2009) Continues that the use of more than one language has diverse impacts on learners' performances and that helps them cognitively as well. Furthermore, the researcher extensively emphasizes the 
use of multiple languages which help in the increase of their knowledge repertoires which is why education to them becomes more comprehensive enhancing their exposure to social, educational, regional and cultural miscellanies.

(Paulsrud, 2017) Believe that the rising norm of multilingualism has heightened educational practices in terms of dynamic and varied range of backgrounds inside the classrooms at undergraduate levels in universities. Furthermore as in third world countries there is an extensive use of multilingualism outside the classrooms. When those multilingual linguistic repertoires will be integrated with the language outside the classrooms then the exposure of students will be better than ever.

(Hornberger, 1990) calls multilingualism as a source of linguistic and ethnic assorted backgrounds and knowledge with which learners get a good exposure in a comprehendible manner required for ESL classrooms. This involves the advancement of learners in more than one language which in diverse backgrounds is a plus point for making rich linguistic repertoire for learners. The same concept has been continued and propagated by (Garcia, 2009).

\section{Research Methodology}

The current research practices qualitative research design as methodology of the study. This kind of qualitative study finds wide-ranging descriptive data most suitable to address the problem. The qualitative type of research generates data through structured, semi-structured and online interviews.

(Dey, 1993) recommended qualitative research analysis methods to be smartest of all the methods even more than surveys. Since this includes multiple data sources like interviewing, observation, analysis, group, single and online interviewing and documentaries. Because of wide range of methods qualitative research methodology is seen to be most suitable and adaptable of all. (Chauhan, 2012) continues that qualitative research methodology has attribution to a varied range of social interaction with participants and helps to get first-hand experience with them hence this seems to be most compatible methods of data collection than others. This research projects uses qualitative research methodology as framework of the study.

\subsection{Data Collection Tools}

The qualitative research study as mentioned by (Dey, 1993) uses several methods of data collection and interpretation. So out of so many methods, the best adaptable among them for this research project were semistructured online interviews.

(Mathers, 1998) et al further describes the semi-structured interviews as the open-ended questions designed by the research prior data collection. This includes thorough analysis of the research questions to structure the questions for interviews in alignment. The researcher designs questions before and during the interviews as per requirement of the topic.

\subsection{Research Participants}

As this research project addresses the second language acquisition in multilingual situation and teachers' strategies of managing such varied range of languages in one classroom. The present study chose ESL teachers from three public sector universities i.e. University of Sindh Jamshoro, Mehran University of Engineering and Technology Jamshoro and Quaid-e-awam University of Engineering Science \& Technology Shaheed Benazirabad. Since this study is about the management of multilingual backgrounds of students by teachers hence the range of teachers is chosen wisely.

\subsection{Sampling}

This research project collected data from public sector universities'. The participants of the study were belonging to varied linguistic backgrounds as well. So to meet the requirements of the research questions, purposive sampling was preferred among other sampling methods. (Monette, 2011) describes that purposive sampling helps researchers to recruit participants of the study based on their familiarity and expertise related to the topic of the study. The participants selected for the study were ten in total $(n=10)$. The distribution of participation is: Three from Mehran University of Engineering \& Technology, Jamshoro, Three from Quaid-e-awam University of Engineering, Science \& Technology, Shaheed Benazirabad, Sindh, Pakistan and four from University of Sindh, Jamshoro. Besides, gender ratio was also balanced. The participants aged from 23 to 28 and belonged to rural and urban Sindh currently based in Hyderabad, Jamshoro and Shaheed Benazirabad.

\subsection{Analysis \& Interpretation}

The study used qualitative interviews which were conducted via online source/ internet. The interviews were audio-recorded for transcription and analysis later on. After the data collection, the audio-recordings' were heard by researcher several times. The transcription of the responses of the participants was done for coding and analysis. The study used content analysis to interpret the data as it helps researchers to divide the descriptive data 
into codes, themes and categories (Creswell, 2008). Further, those codes were divided and analyzed with the help of audio-recordings. Content analysis says (Creswell, 2008) provides the detailed and factual explanation of the responses of participants. It is therefore widely used as a tool for data analysis in qualitative studies.

There has been a great focus on the confidentiality of the names and other demographic information of the participants.

\section{4. $\quad$ Findings \& Discussion}

The data was collected from ten $(\boldsymbol{n}=\mathbf{1 0})$ undergraduate teachers in Hyderabad Sindh Pakistan. For interview, the present researcher made some dominant questions which the teachers were informed before the interview could actually begin. The other questions were made from these dominant questions as a further investigation into the study. The result is presented with respect to categories constructed out of questions used in interview.

\section{Table.1}

Themes, Subthemes and sample responses among undergraduate teachers

Theme Subtheme Sample Response Theme.1: Multilingualism is very much present and it is appreciated or welcomed by learners and teachers both in ESL classrooms

\section{Multilingual backgrounds of learners}

\section{Switching languages}

Theme.2: Multilingualism strategies in ESL classrooms

P3, P4, P5, P6, P7, P8, P9, P10) Rural and Urban areas- (P2) I teach in multilingual classroom. Students come from different I have learners from Palestine, balochistan, laar side of Sindh, utradhi, wicholi sindhi, urdu and Punjabi speakers, siraiki (P1, P2, language groups like Sindhi, Urdu, Balochi and Pashto- (P3, P4)

I switch to Sindhi and Urdu when I feel that they way I gave the task to students isn't fulfilled. (P1, P2, P3, P5, P6, P7, P8, P9,P10) If I do switch then it is Urdu as it acts as lingua.

Medium of Instruction of teachers franca (P3, P7).

English mostly(P1) My students like to take instructions in sindhi or urdu(P2, P4, P8, P9, P10) English only so no confusion occurs (P3, P7).

Translation of complex topics

Makes groups according to their levels and proficiencies

Being humorous and funny

Engaging in dialogues in different language and proficiency groups

Encouragement for using L2

Patient and charging fine

I try to translate into urdu and sindhi language when there is a difficult or complex topic $(\mathrm{P} 1, \mathrm{P} 4, \mathrm{P} 5, \mathrm{P} 6, \mathrm{P} 7$, P8, P9, P10)

I try to ask my students to form group so they can perform better in the class. (P2, P3, P8)

When I am funny and humorous that also helps as a strategy to cater learners in large classes (P2) I try to engage them in groups for better performance (P3, P6, P10)

I encourage them to come in front and speak in English no matter right or wrong and they do it successfully (P3, P7) Being patient in class and sometimes charging them for not using English also works (P6)

Theme.3: Learning Knowledge in mother tongue more preferable than ESL.

Sindhi/native language is more preferred my students are very comfortable in their native language (P1) mostly Sindhi, few Punjabi,

Theme.4: Multilingualism impact: Negative or positive

Balochi and Urdu. (P1) Yes learners feel comfortable in their native language if switched (P3, P4, P5, P6, P7,P8, P9, P10)

In my context three or four languages, in class restricted outside classroom their natives so they can have both impacts because they do not practice outside the class. (P1,P2, P3, P6, P8, P9, P10) Positive- when instructions in their native language (P2, P5) No effect of Multilingualism on learners (P4, P7) 


\section{Discussion}

\section{Multilingualism is very much present and it is appreciated or welcomed by learners and teachers both} in ESL classrooms

The situation of Multilingualism is very much there responded by $(\mathrm{n}=10)$ all the participants. They have learners from diversified backgrounds like educational, cultural, social, political and linguistic. They have wide range of learners from linguistic background people belonging to different regional languages like: Sindhi, Urdu, Balochi, Siraiki, Pashto and dialectal variations in the Sindhi language too.

\section{Multilingualism strategies in ESL classrooms}

There were so many different strategies suggested by undergraduate teachers that they use during their classes to cater the multilingual learners and ESL classroom setting. ( $\mathrm{n}=90 \%)$ teachers believed that one of the strategies that works more than any other is the conversion/ translation of ideas from L2 to L1 for the better understanding of learners and this works for $90 \%$ of them. Few teachers' believed that there happen to be groups of different learners working as a good strategy for Multilingual classrooms said $(n=30)$. Some $(n=30 \%)$ undergraduate teachers believed that making learners engage in dialogue and group making according to their proficiencies is also one of the good strategies to be applied in multilingual situation. Few $(n=20 \%)$ teachers believed that encouragement works better in such situations for learners to speak in front of the class and their peers no matter right or wrong. This strategy allows having a good confidence in learners and they perform better. A very interesting answer came from a teacher $(n=10 \%)$ who believed that being humorous and funny in classroom has a profound effect in multilingual setting and this helps them have their own space and a good environment in class. A teacher $(\mathrm{n}=10 \%)$ also believed that the good strategy is a patient behavior of a teacher in multilingual situation and sometimes charging learners for not using English language may help as positive reinforcement for learners to use English language in ESL classrooms.

\section{Learning Knowledge in mother tongue more preferable than ESL.}

The undergraduate teachers $(n=95 \%)$ believed that ESL learners so deeply have a view that instructions in their mother tongue/ native language effects their performance in a profound way. The teachers had a say that mostly students like to get instructions and lectures in their native language (L1) other than English language (L2).

\section{Multilingualism impact: Negative or positive}

This situation or question had different range of answers/ responses by the undergraduate learners. Some $(n=$ 95\%) teachers believed that multilingual situation in ESL classrooms has both the effects positive and negative on learners performances. Positive because they have to face a variety of languages and there is a fair chance of learning some areas/items cognitive development about few of them (most closely related to their native language) and negative because their native language has a dominant effect on their other languages that they tend to learn which may lead them to failure of multilingual setting. There were few undergraduate teachers $(\mathrm{n}=20 \%)$ who saw multilingualism as completely positive because it helps the learners in their learning in so many ways like exposure to many languages, peer learning and group learning about L2 and their regional languages, However, there were few teachers $(n=20 \%)$ which said that Multilingualism has no impact on learners performance so far as we live in a society where we are exposed to many languages in and outside the classrooms so since, they are there hence leave no impression or affect on learners' performances also, learners' tend to use their (L1) everywhere and (L2) is just there in ESL classrooms so there is no higher impact on ESL learning and learners' performances.

\section{Conclusion}

English language plays a vital role in the world market. Most of the everyday activities including education, job, and others are carried out in English language. Besides, English language is also considered a symbol of prestige and honor. However, in case of Education English has opened so many other gates leaving behind the doors for regional languages closed and at a risk. In Sindh Pakistan, most of the focus of ESL learning is on English Language and no say for any regional language. The students have diverse educational backgrounds. The students who have studied English language from earlier classes have no difficulty in understanding these subjects in English language. On the contrary, most students in government colleges have poor skills in English language which hinder their understanding of the concepts. The study shows that the learners have a profound effect of Multilingualism in their lives and they have a feel that they can learn any language in a better way when intended to be explained in their native language (L1). This situation is there and prevailing in third world countries more than any other area of the world.

\section{References}

1. Ahmed, S.I (2011). Issue of Medium of Instruction in Pakistan. International Journal of Social sciences and Education. Vol.1 (1)

2. Buhmann, D. \& Trudell, B (2008). Mother Tongue Matters: Local Language as a key to Effective learning: UNESCO Report, France 
3. Alm, R., \& Colnerud, G. (2015). Teachers' experiences of unfair grading. Educational Assessment, 20, 132150.

4. Bonesronning, H. (1998). The variation in teachers' grading practices: Causes and consequences. Economics of Education Review, 18, 89-105

5. Brown, C. L. (2007). Strategies for making social studies texts more comprehensible for English-language learners. The Social Studies, 98(6), 185-188

6. Ellis, R. (1997). Second language acquisition. Oxford: Oxford University Press

7. Radha M. K. Nambiar (2007). Enhancing academic literacy among tertiary learners: A Malaysian experience. 3L: Language, Linguistics, Literature, The Southeast Asian Journal of English Language Studies. Vol 13, 77-94 Rohaila Y, Norasmah O, Faridah K. 2005.

8. J. Lyons. Language and Linguistics: An Introduction, Cambridge University Press, Cambridge, 1981.

9. M. Mwololo. Are You Fluent in Your Mother Language? In Daily Nation, Living, February 20th, Nation Media Group, Nairobi, 3, 2008.

10. Björklund, M. (2008). Conditions for EFL Learning and Professional Development. FinlandSwedish Learner and Teacher Perspectives. Doctoral dissertation. Åbo: Åbo Akademi University Press.

11. Coelho, E. (2009). Language and Learning in Multilingual Classrooms. A Practical Approach. Bristol, UK: Multilingual Matters

12. McRae, K. D. (1997). Conflict and compromise in Multilingual Societies. Finland. Volume 3. Waterloo, Canada: Wilfrid Laurier University Press.

\section{Structured Interview questions:}

1) Do you have multilingual classrooms? (Students coming from different backgrounds)

2) How often and when do you switch between more than one language?

3) What do you do as a strategy being a teacher to cater multilingual students in a class?

4) When do your students feel comfortable in your medium of instruction?

5) Do you think multilingual situation affects positively or negatively towards learners performance and learning overall? Please give elaborate answer.

6) What is your best effort to cater multilingual students in a class leaving behind a positive impact on learners' performance? (What and how do you manage students of multiple languages and their interest in class?) 